\title{
Altered calcium handling is an early sign of streptozotocin-induced diabetic cardiomyopathy
}

\author{
LÁSZLÓ LIGETI ${ }^{1}$, ORSOLYA SZENCZI ${ }^{1}$, CHRISTINA M. PRESTIA ${ }^{1}$, CSABA SZABÓ $^{1}$, \\ KATALIN HORVÁTH ${ }^{2}$, ZOLTÁN L. MARCSEK ${ }^{2}$, RUUD G.P.M. VAN STIPHOUT ${ }^{3}$, \\ NATAL A.W. VAN RIEL ${ }^{3,4}$, JORN OP DEN BUIJS ${ }^{3}$, GER J. VAN DER VUSSE ${ }^{5}$ and TAMÁS IVANICS ${ }^{1}$ \\ ${ }^{1}$ Institute of Human Physiology and Clinical Experimental Research, Semmelweis University, \\ H-1082 Budapest, Üllöi út 78/A; ${ }^{2}$ Department of Molecular and Cell Biology, National Institute of \\ Chemical Safety, H-1450 Budapest, Pf. 36, Hungary; Departments of ${ }^{3}$ Biomedical Engineering, and \\ ${ }^{4}$ Electrical Engineering, Eindhoven University of Technology, $5600 \mathrm{MB}$, Eindhoven; ${ }^{5}$ Department of Physiology, \\ Cardiovascular Research Institute Maastricht (CARIM), Maastricht University, 6200 MD, Maastricht, The Netherlands
}

Received December 20, 2005; Accepted February 3, 2006

\begin{abstract}
The main objective of the present study was to determine alterations of calcium handling in the diabetic rat heart during the transition from adaptive to maladaptive phase of cardiomyopathy. By inhibiting the nuclear enzyme poly(ADP-ribose) polymerase (PARP), we also investigated the possible role of this enzyme in the sequence of pathological events. Six weeks after induction of type I diabetes by injection of streptozotocin in rats, the hearts were perfused according to Langendorff. Intracellular-free calcium $\left(\mathrm{Ca}^{2+}{ }_{\mathrm{i}}\right)$ levels were measured by surface fluorometry using Indo-1 AM. Cyclic changes in $\mathrm{Ca}^{2+}{ }_{\mathrm{i}}$ concentrations and hemodynamic parameters were measured simultaneously. The hearts were challenged by infusion of isoproterenol. Six weeks of diabetes resulted in reduced inotropy and lusitropy. The diabetic hearts (DM) expressed a significantly elevated end-diastolic $\mathrm{Ca}^{2+}{ }_{\mathrm{i}}$ level (control, $111 \pm 20$ vs DM, 221 $35 \mathrm{nM}$ ). The maximal transport capacity of SERCA2a and conductance of RyR2 were reduced. These changes were not accompanied by major alterations in the tissue content of SERCA2a, RyR2, phospholamban and $\mathrm{Na}^{+} / \mathrm{Ca}^{2+}$ exchanger. In response to $\mathrm{B}$-adrenergic activation, SERCA2a transport capacity and RyR 2 conductance were stunted in the DM hearts. Inhibition of PARP induced minor changes in the mechanical function and calcium handling of the DM hearts. In conclusion, the observed changes in contractility and in $\mathrm{Ca}^{2+}{ }_{\mathrm{i}}$ handling are most likely attributable
\end{abstract}

Correspondence to: Dr Csaba Szabó, Institute of Human Physiology and Clinical Experimental Research, Semmelweis University, H-1082 Budapest, Üllöi út 78/A, Hungary

E-mail: szabocsaba@aol.com

Key words: diabetes, cardiac function, intracellular calcium handling, SERCA2A, RyR2, poly(ADP-ribose) polymerase to functional disturbances of SERCA2a and RyR2 in this transitional phase of diabetes. At this stage of diabetes, PARP does not appear to play a significant pathogenetic role in the alterations in contractile function and calcium handling.

\section{Introduction}

Diabetes mellitus is an insidious systemic disease, gradually leaving its mark on every organ system. Vascular disease and atherosclerosis are closely related to the progression of diabetes. Numerous studies have shown that prolonged diabetes results in myocardial contractile dysfunction without apparent coronary disease $(1,2)$. The alterations include impaired cardiac contractility and diastolic function. The pathophysiological mechanisms behind the impaired cardiac function are multifactorial. Derangement of intracellular calcium handling plays a pivotal role in the decreased heart function $(3,4)$. Numerous studies have also implicated a role for various oxidants and free radicals, and downstream pathways, such as the one governed by the nuclear enzyme poly(ADP-ribose) polymerase (PARP), which may also alter $\mathrm{Ca}^{2+}{ }_{\mathrm{i}}$ homeostasis (5-8). Other studies on short-term effects of diabetes have shown no apparent signs of depressed cardiac function within the first 4 weeks of the disease $(9,10)$. Findings in a rat model of streptozotocin-induced diabetes indicate that, in between 4 and 8 weeks after the onset of diabetes, a transition state develops during which signs of malfunctioning become evident $(1,11)$. Since adequate intracellular calcium handling is essential in normal cardiac functioning it is feasible that derangement of intracellular calcium homeostasis is a hallmark of transition from apparently normal to overt malfunctioning. Unfortunately, detailed information regarding calcium handling during this period is scarce, hampering an understanding of the mechanisms underlying the manifestation of diabetic cardiomyopathy.

Studies on cardiomyocytes isolated from hearts suffering manifest diabetic cardiomyopathy have revealed that both release and removal of $\mathrm{Ca}^{2+}{ }_{\mathrm{i}}$ to and from the sarcoplasm are disturbed $(3,12)$. Moreover, the cellular content of proteins 
involved in sequestration of $\mathrm{Ca}^{2+}{ }_{\mathrm{i}}$ [sarcoplasmic reticulum $\mathrm{Ca}^{2+}$-ATPase (SERCA2a), phospholamban (PLB), $\mathrm{Na}^{+} / \mathrm{Ca}^{2+}$ exchanger (NCX) and sarcolemmal $\mathrm{Ca}^{2+}$-ATPase] are reduced and their functional state is altered (12-14). A previous study of ours has shown that, in the intact heart under basal conditions, neither calcium handling, nor hemodynamic function were impaired 4 weeks after the onset of diabetes (15).

The main objective of the present study was to determine alterations in calcium handling, if any, in the diabetic heart during the transitional phase. To obtain detailed information about myocardial calcium homeostasis, we have measured calcium transients in the intact beating heart using an epifluorescence technique and estimated the kinetic properties of two key proteins, SERCA2a and RyR2, using a recently developed mathematical model (15). Moreover, the cardiac content of a set of proteins including SERCA2a, PLB, NCX and RyR2 were determined by Western blot analysis. The experiments were performed on hearts obtained from rats rendered diabetic for 6 weeks, since literature data strongly suggest that this time period corresponds with the transitional phase. The hearts were studied both under basal conditions and during $B$-adrenergic challenge. An additional aim of this study was to investigate whether activation of PARP contributes to transition from an adaptive to maladaptive state. Hence, we proceeded to test the effect of pharmacological inhibition of PARP on the changes in contractile function and calcium handling, because of the role of this pathway in diabetic cardiomyopathy (5) and also because recent results indicate that, in certain experimental models of cardiomyopathy (such as the one elicited by the cardiotoxic drug doxorubicin), there is a relationship between alterations in myocardial calcium handling and PARP activation (16).

\section{Materials and methods}

General. Diabetes was induced in rats by a single injection of streptozotocin. Six weeks after the treatment, the hearts were excised and perfused according to Langendorff with KrebsHenseleit solution. Measurement of left ventricular pressure was accomplished via introduction of a balloon into the left ventricle and coronary flow was obtained using an ultrasonic transducer. Indo-1 fluorescent dye was loaded into the heart for determination of intracellular calcium concentration. Cardiac function was challenged through $ß$-adrenoceptor stimulation by isoproterenol. Hemodynamic performance and functional parameters of intracellular calcium cycling were assessed. A computational model of cardiomyocyte calcium fluxes was used for estimation of kinetic parameters of myocardial calcium handling proteins by a recently developed mathematical model (15). The tissue content of a set of calcium handling proteins was assessed using Western blot analysis.

Animals used and induction of diabetes. Male Sprague-Dawley rats ranging in body weight from 200 to $250 \mathrm{~g}$ were maintained in an animal facility with a 12-h light and 12-h dark cycle with free access to food and water. Experiments on animals followed the Guide for the Care and Use of Laboratory Animals published by the US National Institutes of Health (NIH Publication No. 85-23, revised 1996), and the study protocol was approved by the Laboratory Animals Committee of the Semmelweis University of Budapest.

Under anesthesia, the animals were made diabetic with streptozotocin (STZ, $70 \mathrm{mg} / \mathrm{kg}$ i.v.) (DM, n=7) as described previously (15). Age-matched controls were treated with vehicle only $(C, n=8)$. STZ rats were given a $5 \%$ glucose solution to drink. In a last experimental group, STZ-treated rats were orally given $20 \mathrm{mg} /$ body weight of the PARP inhibitor, PJ34, dissolved in water during the treatment period, starting from the 4th week after the induction of DM (DM+PJ, $\mathrm{n}=6$ ). The current treatment protocol has previously been shown to achieve maximal inhibition of myocardial PARP activity in vivo $(5,17)$. In a previous study, we have shown that PJ treatment per se had no effect on hemodynamic function or on the parameters of intracellular calcium handling; hence, in this set of experiments, no control animals received PJ treatment (16). Blood glucose concentration was measured using a glucose meter (77 Elektronika, Budapest, Hungary).

Langendorff heart preparation - Indo-1 AM loading and fluorescence measurement. The general procedure to measure hemodynamic parameters and fluorescence signals in a beating heart preparation was outlined previously in detail (16).

Six weeks after the initiation of diabetes, the animals were anesthetized by $40 \mathrm{mg} / \mathrm{kg}$ i.p. pentobarbital (NembutalSanofi, Budapest, Hungary). Hearts were quickly removed and mounted on a Langendorff perfusion apparatus and perfusion was initiated with a modified Krebs-Henseleit solution containing $118 \mathrm{mM} \mathrm{NaCl}, 4.3 \mathrm{mM} \mathrm{KCl}, 25 \mathrm{mM}$ $\mathrm{NaHCO}_{3}, 1.2 \mathrm{mM} \mathrm{MgSO}$, $1.2 \mathrm{mM} \mathrm{KH}_{2} \mathrm{PO}_{4}, 0.5 \mathrm{mM}$ NaEDTA, $2.0 \mathrm{mM} \mathrm{CaCl}$, $11 \mathrm{mM}$ glucose, $5 \mathrm{mM}$ pyruvate (all chemicals purchased from Sigma, Budapest, Hungary), which was equilibrated with $95 \% \mathrm{O}_{2}$ and $5 \% \mathrm{CO}_{2}$. The temperature of the buffer was maintained at $37^{\circ} \mathrm{C}$ and $\mathrm{pH}$ was adjusted to 7.4. The perfusion pressure was set to $70 \mathrm{~mm} \mathrm{Hg}$.

Details of loading of the heart with the dye and details of optical measurements were published elsewhere (15). In short, hearts were loaded with $6.25 \mu \mathrm{M}$ Indo-1 AM and were illuminated at $355 \mathrm{~nm}$, the emitted light was recorded at $400 \mathrm{~nm}\left(\mathrm{Ca}^{2+}{ }_{\mathrm{i}}\right.$-bound dye $)$ and $506 \mathrm{~nm}\left(\mathrm{Ca}^{2+}{ }_{\mathrm{i}}\right.$-free dye $)$. Both the fluorescence and reflectance signals together with the hemodynamic parameters were recorded and stored for offline analysis (Hemosys, Experimetria, Budapest, Hungary).

After loading of the dye and 20-min washout, the fluorescence signals were recorded in the basal state. Thereafter, the hearts were subjected to $5.0 \mathrm{nM}$ isoproterenol (Sigma) infusion via the aortic line. Heart rate, systolic and diastolic pressure stabilized in approximately $5 \mathrm{~min}$ after the start of infusion, at which stage the fluorescence signals were recorded.

Data analysis and interpretation. Individual fluorescence signals were corrected for closed shutter background and tissue autofluorescence of the unloaded tissue [correction for redox changes of $\left.\mathrm{NAD}(\mathrm{P})^{+} / \mathrm{NAD}(\mathrm{P}) \mathrm{H}\right] \cdot \mathrm{Ca}^{2+}{ }_{\mathrm{i}}$ concentration was calculated using the formula determined by Grynkiewicz et al (18). The Indo-1 dissociation constant $\left(\mathrm{K}_{\mathrm{d}}\right)$ for calcium was determined previously at $844 \mathrm{nM}$ (19). The fluorescent ratios at zero $\mathrm{Ca}^{2+}{ }_{\mathrm{i}}\left(\mathrm{R}_{\min }\right)$ and at saturating $\mathrm{Ca}^{2+}{ }_{\mathrm{i}}\left(\mathrm{R}_{\max }\right)$ were determined in separate experiments. Two control hearts loaded with Indo-1 were treated with $20 \mu \mathrm{M}$ BAPTA-AM to 


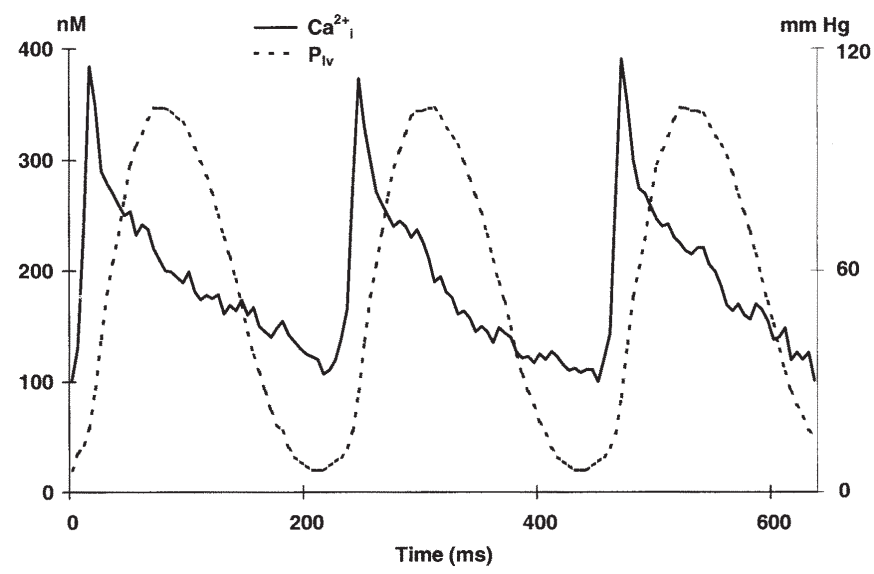

Figure 1. Representative tracings of $\mathrm{Ca}^{2+}{ }_{\mathrm{i}}$ transient and left ventricular pressure $\left(\mathrm{P}_{\mathrm{lv}}\right)$ of an intact, perfused control rat heart. Note that the peak of the calcium transient precedes the peak of the left ventricular pressure by $30-40 \mathrm{~ms}$

define $\mathrm{R}_{\min }$ and two other control hearts were infused with $1 \mu \mathrm{M}$ 4-bromo-calcium-ionophore (A23187) to determine $\mathrm{R}_{\max }$. The calcium transient was assessed to determine systolic and diastolic $\mathrm{Ca}^{2+}{ }_{\mathrm{i}}$ and $\mathrm{Ca}^{2+}{ }_{\mathrm{i}}$ amplitude (Fig. 1). Maximal rates of rise of $\mathrm{Ca}^{2+}{ }_{\mathrm{i}}\left(+\mathrm{dCa}^{2+}{ }_{\mathrm{i}} / \mathrm{dt}_{\max }\right)$ and decline of $\mathrm{Ca}^{2+}{ }_{\mathrm{i}}\left(-\mathrm{dCa}^{2+}{ }_{\mathrm{i}} / \mathrm{dt}_{\max }\right)$ were obtained as indices for the rate of calcium release from the sarcoplasmic reticulum (SR) and sequestration back into the SR, respectively.

Computation of kinetic parameters of calcium handling proteins. For computation of the kinetic model parameters in more progressed diabetes, the same $\mathrm{Ca}^{2+}{ }_{\mathrm{i}}$ handling model was used as for the parameter analysis at an early stage of diabetes as published previously (15). In brief, this one-compartment model simulates the intracellular calcium concentration in a single heartbeat and includes calcium influx by the ryanodine (RyR2) channels, calcium removal by SR $\mathrm{Ca}^{2+}$-ATPase (SERCA2a) and intracellular calcium buffering. In the rat heart, RyR2 and SERCA2a account for $92 \%$ of the generation of the $\left[\mathrm{Ca}^{2+}\right]_{\mathrm{i}}$ transient (20). This model is used to estimate kinetic parameters of RyR2 and SERCA2a by minimizing the square error between the simulated and measured calcium concentrations.

The rate of release of calcium from the SR is described by the RyR2 activity $\mathrm{V}_{\mathrm{RyR} 2}\left(\mathrm{nMs}^{-1}\right)$, which is taken as a 4th-order sigmoid function of the cardiac cycle time $\mathrm{T}$ as follows:

$$
\mathrm{V}_{\mathrm{RyR} 2}=\mathrm{k}_{\mathrm{ch}}\left(1-\frac{\mathrm{t}^{4}}{\mathrm{t}^{4}+\mathrm{t}_{0.5}^{4}}\right) \quad 0 \leq \mathrm{t} \leq \mathrm{T}
$$

It is assumed that, at $\mathrm{t}=0$, the calcium upstroke is maximal, which implies maximal $\mathrm{V}_{\mathrm{RyR} 2}$. The parameter $\mathrm{k}_{\mathrm{ch}}\left(\mathrm{nMs}^{-1}\right)$ is defined as this maximal rate of calcium influx. The parameter $\mathrm{t}_{0.5}(\mathrm{~ms})$ is the moment in time at which half of the $\mathrm{V}_{\mathrm{RyR} 2}$ is reached.

Sequestration of calcium into the SR by SERCA2a $\left[\mathrm{V}_{\text {SERCA2a }}\left(\mathrm{nMs}^{-1}\right)\right]$ is described by Hill kinetics with maximal activity $\mathrm{V}_{\max }$ and affinity $\mathrm{K}_{\mathrm{m}}$ which defines the sensitivity of SERCA2a, as follows:

$$
\mathrm{V}_{\text {SERCA2a }}=\frac{\mathrm{V}_{\max }}{\left(\mathrm{K}_{\mathrm{m}} /[\mathrm{Ca}]_{\mathrm{i}}\right)^{4}+1}
$$

The calcium buffering effects of calmodulin, troponin $\mathrm{C}$ and proteins associated with the SR membranes are modeled as a fractional buffering B by applying a rapid buffer approximation $(15,21)$.

The change in free intracellular calcium concentration is described by the model state equation as follows:

$$
\frac{\mathrm{d}\left[\mathrm{Ca}^{2+}\right]}{\mathrm{dt}}=\frac{\mathrm{V}_{\mathrm{RyR} 2}-\mathrm{V}_{\text {SERCA2a }}}{\mathrm{B}}
$$

In each dataset, up to 40 transients were selected in artifactfree regions of the measured calcium concentration. These transients were averaged and the variance for each data point was calculated. For the maximum likelihood estimator, a nonlinear least square error between the simulated model transient and the averaged measured transients, weighted by the reciprocal of the variance in the sample points, was used. The model parameters, $\mathrm{k}_{\mathrm{ch}}, \mathrm{t}_{0.5}, \mathrm{~V}_{\max }$ and $\mathrm{K}_{\mathrm{m}}$, were estimated with non-negative constraints using numerical optimization.

Western blot analysis. Quantitative Western blot analysis was performed to determine the tissue content of SERCA2a, PLB, NCX and RyR2 as described by Bradford (22). The antibodies used were SERCA2a, PLB, RyR2 (Affinity Bioreagents, Golden, CO, USA), and NCX (Abcam Ltd., Cambridge, UK). Horseradish peroxidase-linked anti-mouse IgG (Amersham, Oakville, ON, Canada) was used as secondary antibody. Protein samples ( $25 \mu \mathrm{g}$ of total protein/lane) were separated by electrophoresis for $45 \mathrm{~min}$ at $200 \mathrm{~V}$ using $5 \%$ (for SERCA2a, NCX and RyR) 12\% (for SERCA2a and NCX) and 18\% (for SERCA2a, NCX and PLB) gels (Bio-Rad Ready Gel, CA USA).

Statistics. Results are expressed as mean \pm SEM. Statistical analysis was carried out using one-way analysis of variance followed by Fisher's post-hoc test. A statistically significant difference of $p<0.05$ was accepted throughout. Effects of isoproterenol infusion were analyzed by Student's t-test $(\mathrm{p}<0.05)$.

\section{Results}

General effects of STZ treatment. Body mass (BM), heart mass (HM) and blood glucose in 6-week STZ diabetic rats are summarized in Table I. Body and heart mass were significantly reduced compared to control. However, reduction of body mass in the PJ34-treated animals was significantly less than that of those with non-treated diabetic hearts. Blood glucose levels rose considerably in the diabetic groups. The HM:BM ratio increased significantly in diabetic animals.

Hemodynamic function. We found no differences in systolic and developed pressures between control, DM and DM+PJ34 hearts in a basal state (Table II). Infusion with isoproterenol induced similar increases in systolic and developed pressures in all groups. The heart rates of the diabetic hearts (both DM and DM+PJ34 groups) were significantly slower as compared to control and they showed an expected increase upon $\beta$ adrenergic activation in all groups. While the absolute values of coronary flow decreased in the diabetic groups (data not shown), the normalized coronary flow did not show significant changes between the three groups, either under basal or 
Table I. General effects of STZ treatment in control $(C, n=8)$, diabetic (DM, n=7) and diabetic + PJ34 rats $(\mathrm{DM}+\mathrm{PJ}, \mathrm{n}=6)$.

\begin{tabular}{llc}
\hline Body mass $(\mathrm{g})$ & $\mathrm{C}$ & $407 \pm 10$ \\
& $\mathrm{DM}$ & $209 \pm 7^{\mathrm{a}}$ \\
& $\mathrm{DM}+\mathrm{PJ}$ & $254 \pm 7^{\mathrm{a}, \mathrm{b}}$ \\
Heart mass $(\mathrm{g})$ & $\mathrm{C}$ & $1.45 \pm 0.06$ \\
& $\mathrm{DM}$ & $0.99 \pm 0.05^{\mathrm{a}}$ \\
& $\mathrm{DM}+\mathrm{PJ}$ & $1.13 \pm 0.05^{\mathrm{a}}$ \\
Heart mass/body mass $(\mathrm{mg} / \mathrm{g})$ & $\mathrm{C}$ & $3.6 \pm 0.1$ \\
& $\mathrm{DM}$ & $4.8 \pm 0.2^{\mathrm{a}}$ \\
& $\mathrm{DM}+\mathrm{PJ}$ & $4.5 \pm 0.2^{\mathrm{a}}$ \\
Blood glucose (mmol/l) & $\mathrm{C}$ & $9.2 \pm 0.6$ \\
& $\mathrm{DM}$ & $24.2 \pm 0.2^{\mathrm{a}}$ \\
& $\mathrm{DM}+\mathrm{PJ}$ & $23.7 \pm 0.8^{\mathrm{a}}$ \\
\hline
\end{tabular}

Statistically significant differences $(\mathrm{p}<0.05)$ are indicated as follows: ${ }^{\mathrm{a}}$ control vs DM or DM+PJ hearts, ${ }^{\mathrm{b}} \mathrm{DM}$ vs $\mathrm{DM}+\mathrm{PJ}$ hearts.

stimulated states. The rate-pressure product showed a minor, non-significant decrease in both diabetic groups in a basal state. The effect of $ß$-adrenergic stimulation on rate-pressure product was about the same in any of the groups. In the DM hearts, the flow demand ratio tended to be increased in the basal state, indicating luxurious flow in these hearts, which was not observed in the DM+PJ34 hearts. Both in the control and diabetic hearts, flow demand ratio decreased significantly during $\beta$-adrenergic activation. However, under this condition, this parameter in $\mathrm{DM}+\mathrm{PJ} 34$ hearts tended to be lower than that observed in DM hearts (borderline significance, $\mathrm{p}=0.07$ ).

The positive and negative derivate of $\mathrm{P}_{1 v} / \mathrm{dt}_{\max }$ was lower in both diabetic groups indicating that both the inotropic and lusitropic state of the diabetic hearts deteriorated. B-adrenergic treatment increased both parameters significantly in all groups, but the difference between the control and diabetic groups, which was observed in the basal state, remained evident during isoproterenol infusion (Fig. 2).

Intracellular $\mathrm{Ca}^{2+}{ }_{i}$ handling. The end-diastolic levels of $\mathrm{Ca}^{2+}{ }_{\mathrm{i}}$ significantly increased in the diabetic hearts $(\mathrm{C}, 111 \pm 20$ vs DM, $221 \pm 35$ and $\mathrm{DM}+\mathrm{PJ} 34,210 \pm 23 \mathrm{nM}$ ). Isoproterenol infusion resulted in a considerable elevation of this parameter in all groups (Fig. 3), the difference between the control and diabetic groups remained statistically significant. The amplitude of the $\mathrm{Ca}^{2+}{ }_{\mathrm{i}}$ transient was similar in control and diabetic hearts, and it increased significantly during $\beta$-adrenergic activation in all groups.

Table II. Hemodynamic function in control $(C, n=8)$, diabetic $(D M, n=7)$ and diabetic + PJ34 hearts $(D M+P J, n=6)$, under normal conditions and challenged with $5.0 \mathrm{nM}$ isoproterenol.

\begin{tabular}{|c|c|c|c|}
\hline & & Basal & $5.0 \mathrm{nM}$ isoproterenol \\
\hline \multirow[t]{3}{*}{ Systolic $\mathrm{P}_{\mathrm{lv}}(\mathrm{mm} \mathrm{Hg})$} & $\mathrm{C}$ & $111 \pm 8$ & $142 \pm 6^{b}$ \\
\hline & DM & $111 \pm 5$ & $142 \pm 6^{b}$ \\
\hline & $\mathrm{DM}+\mathrm{PJ}$ & $109 \pm 11$ & $127 \pm 8^{\mathrm{b}}$ \\
\hline \multirow{3}{*}{ Diastolic $\mathrm{P}_{\mathrm{lv}}(\mathrm{mm} \mathrm{Hg})$} & $\mathrm{C}$ & $9 \pm 0.2$ & $8 \pm 0.3$ \\
\hline & DM & $8 \pm 0.1$ & $8 \pm 0.2$ \\
\hline & $\mathrm{DM}+\mathrm{PJ}$ & $8 \pm 0.1$ & $7 \pm 0.1$ \\
\hline \multirow[t]{3}{*}{ Developed pressure (mm Hg) } & $\mathrm{C}$ & $102 \pm 8$ & $134 \pm 6^{b}$ \\
\hline & $\mathrm{DM}$ & $103 \pm 5$ & $134 \pm 6^{b}$ \\
\hline & $\mathrm{DM}+\mathrm{PJ}$ & $101 \pm 11$ & $120 \pm 7^{b}$ \\
\hline \multirow{3}{*}{ Heart rate (bpm) } & $\mathrm{C}$ & $270 \pm 7$ & $390 \pm 14^{b}$ \\
\hline & $\mathrm{DM}$ & $219 \pm 16^{\mathrm{a}}$ & $319 \pm 21^{\mathrm{a}, \mathrm{b}}$ \\
\hline & $\mathrm{DM}+\mathrm{PJ}$ & $236 \pm 9^{a}$ & $337 \pm 20^{\mathrm{a}, \mathrm{b}}$ \\
\hline \multirow[t]{3}{*}{ Normalized coronary flow $\left(\mathrm{ml} \mathrm{min}{ }^{-1} \mathrm{~g}^{-1}\right)$} & $\mathrm{C}$ & $12.8 \pm 0.8$ & $13.1 \pm 0.7$ \\
\hline & $\mathrm{DM}$ & $13.1 \pm 1.2$ & $14.1 \pm 0.8$ \\
\hline & $\mathrm{DM}+\mathrm{PJ}$ & $11.7 \pm 1.1$ & $11.3 \pm 1$ \\
\hline \multirow[t]{3}{*}{ Rate-pressure product (mm Hg bpm) } & $\mathrm{C}$ & $2.74 \cdot 10^{4} \pm 1.51 \cdot 10^{3}$ & $5.24 \cdot 10^{4} \pm 3.3 \cdot 10^{3 \mathrm{~b}}$ \\
\hline & DM & $2.23 \cdot 10^{4} \pm 1.51 \cdot 10^{3}$ & $4.37 \cdot 10^{4} \pm 4.33 \cdot 10^{3 \mathrm{~b}}$ \\
\hline & $\mathrm{DM}+\mathrm{PJ}$ & $2.39 \cdot 10^{4} \pm 2.84 \cdot 10^{3}$ & $4.05 \cdot 10^{4} \pm 3.43 \cdot 10^{3 b}$ \\
\hline \multirow[t]{3}{*}{ Flow demand ratio ( $\mathrm{ml} \mathrm{mm} \mathrm{Hg}^{-1} \mathrm{~g}^{-1}$ ) } & $\mathrm{C}$ & $4.66 \cdot 10^{-4} \pm 0.93 \cdot 10^{-5}$ & $2.54 \cdot 10^{-4} \pm 7.44 \cdot 10^{-5 b}$ \\
\hline & DM & $6.05 \cdot 10^{-4} \pm 1.21 \cdot 10^{-5}$ & $3.4 \cdot 10^{-4} \pm 3.44 \cdot 10^{-5 b}$ \\
\hline & $\mathrm{DM}+\mathrm{PJ}$ & $4.97 \cdot 10^{-4} \pm 0.77 \cdot 10^{-5}$ & $2.74 \cdot 10^{-4} \pm 3.2 \cdot 10^{-5 b}$ \\
\hline
\end{tabular}

Statistically significant differences $(\mathrm{p}<0.05)$ are indicated as follows: ${ }^{\mathrm{a}}$ control vs DM or DM+PJ hearts, basal vs isoproterenol. Flow demand ratio was calculated as normalized coronary flow divided by heart rate-developed pressure product. 


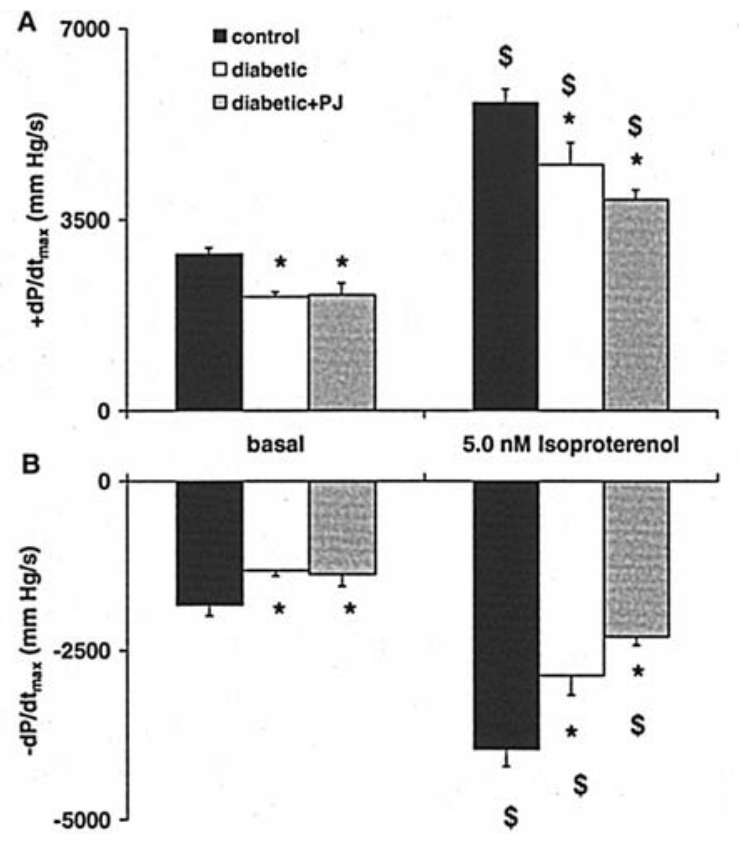

Figure 2. Changes in contractile activity in $\mathrm{C}(\mathrm{n}=8), \mathrm{DM}(\mathrm{n}=7)$ and $\mathrm{DM}+\mathrm{PJ}$ hearts $(n=6)$ under basal conditions and during isoproterenol infusion. $+\mathrm{dP} / \mathrm{dt}_{\max }$, the maximal positive first derivate of $\mathrm{LV}$ pressure; $-\mathrm{dP} / \mathrm{dt}_{\max }$, the maximal negative first derivate of LV pressure. Statistically significant differences $(\mathrm{p}<0.05)$ are indicated as follows: *control vs DM or DM+PJ hearts, ${ }^{\$}$ basal vs isoproterenol.

Fig. 4 shows the estimated rates of release and removal of calcium to and from the sarcoplasm, $+\mathrm{dCa}^{2+}{ }_{\mathrm{i}} / \mathrm{dt}_{\max }$ and $-\mathrm{dCa}^{2+} / \mathrm{dt}_{\max }$, respectively. Under basal conditions, we found no significant differences in $+/-\mathrm{dCa}^{2+} / \mathrm{dt}_{\max }$ between the three groups. The maximum release and removal rates of calcium were accelerated in response to $\beta$-adrenergic activation in all groups to the same extent.

Fig. 5 shows the calculated values of the kinetic parameters of SERCA2a and RyR2. Both the $\mathrm{V}_{\max }$ of SERCA2a and the conductance $\left(\mathrm{k}_{\mathrm{ch}}\right)$ of RyR2 were significantly reduced in the DM hearts as compared to the control. During isoproterenol infusion, this difference was further exaggerated. Treatment of the diabetic animals with PJ34 reversed the tendency of $\mathrm{V}_{\max }$ reduction under a basal state, which was not observed

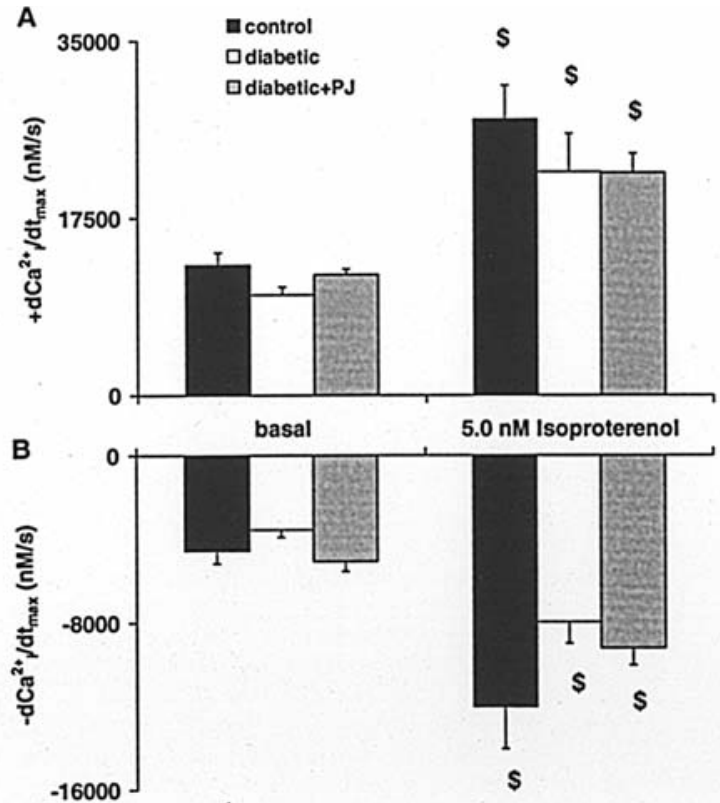

Figure 4. Changes in the dynamic parameters of the $\mathrm{Ca}^{2+}$ transient in $\mathrm{C}$ $(n=8), D M(n=7)$ and DM+PJ hearts $(n=6)$ under basal conditions and during isoproterenol infusion. (A) $+\mathrm{dCa}^{2+}{ }_{\mathrm{i}} / \mathrm{dt}_{\max }$; (B) $-\mathrm{dCa}^{2+}{ }_{\mathrm{i}} / \mathrm{dt}_{\max }$. Statistically significant differences $(\mathrm{p}<0.05)$ are indicated as follows: \$basal vs isoproterenol.

during $B$-adrenergic activation. In the control and DM-PJ hearts, $B$-adrenergic activation resulted in a significant increase in RyR2 conductivity which was not observed in the DM hearts. As opposed to the observed changes in $\mathrm{V}_{\max }$ and $\mathrm{k}_{\mathrm{ch}}$, the affinity of SERCA2a to calcium and the index of RyR2 gating $\left(\mathrm{t}_{0.5}\right)$ remained unchanged during the course of the disease. In response to isoproterenol infusion, the apparent $\mathrm{K}_{\mathrm{m}}$ of SERCA2a increased in the control and DM-PJ groups, while $\mathrm{t}_{0.5}$ remained unchanged.

Tissue content of calcium handling proteins. Representative quantitative immunoblots of SERCA2a, phospholamban, RyR2 and NCX are shown in Fig. 6. Table III summarizes the relative tissue content of these calcium handling proteins. In general, the tissue content of these proteins was not
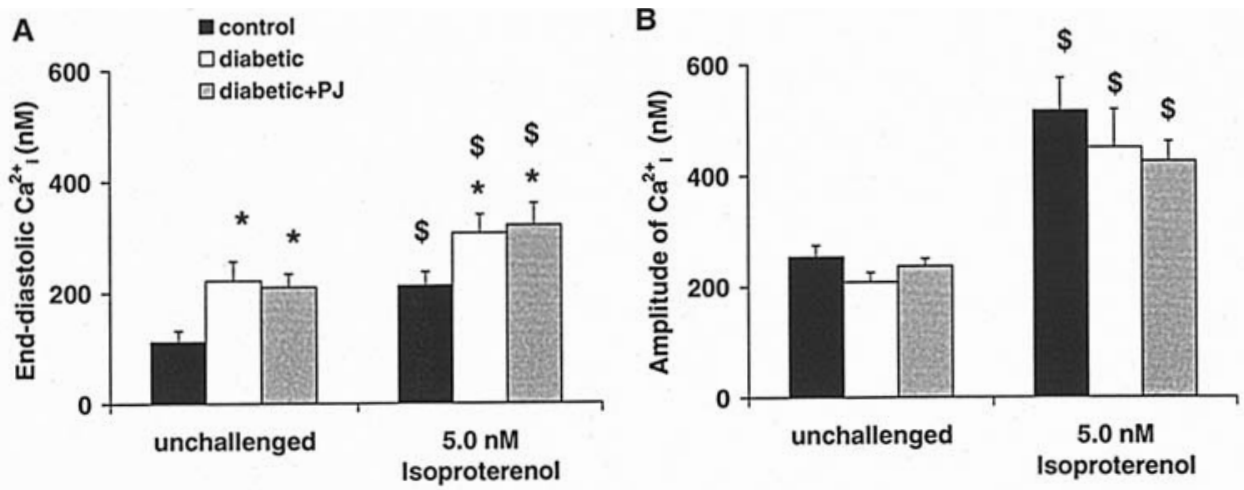

Figure 3. Changes in end-diastolic $\mathrm{Ca}^{2+}{ }_{\mathrm{i}}$ levels $(\mathrm{A})$ and of amplitude of $\mathrm{Ca}^{2+}{ }_{\mathrm{i}}$ transient in $\mathrm{C}(\mathrm{n}=8)$, DM ( $\left.=7\right)$ and $\mathrm{DM}+\mathrm{PJ}$ hearts ( $\left.\mathrm{n}=6\right)$ under basal conditions and during isoproterenol infusion. Statistically significant differences $(\mathrm{p}<0.05)$ are indicated as follows: ${ }^{*}$ control vs DM or DM+PJ hearts, ${ }^{\$}$ basal vs isoproterenol. 

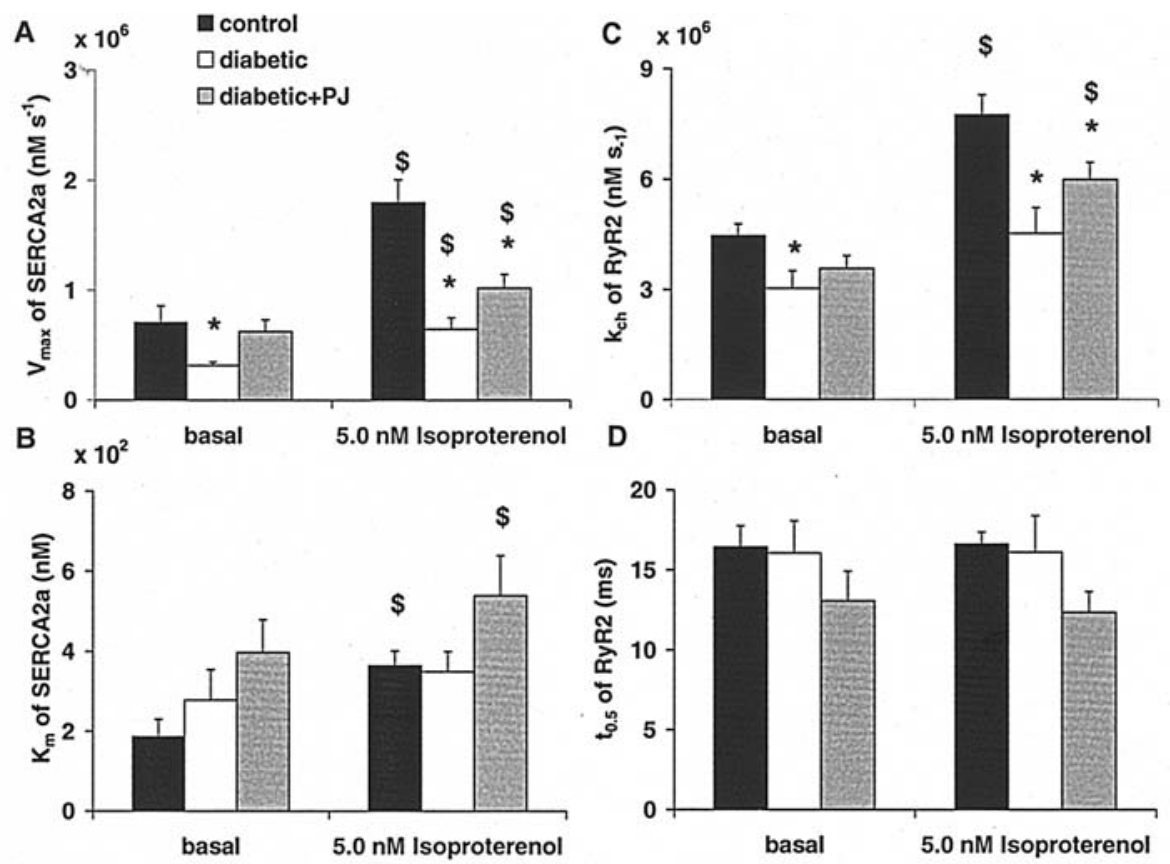

Figure 5. Changes in (A) $\mathrm{V}_{\max }$ of SERCA2a, (B) $\mathrm{K}_{\mathrm{m}}$ of SERCA2a, (C) $\mathrm{k}_{\mathrm{ch}}$ : maximal rate of calcium influx through RyR2; and (D) $\mathrm{t}_{05}$ : the time from maximal to half of the maximal calcium influx by RyR2 in $C(n=8)$, DM $(n=7)$ and DM+PJ hearts $(n=6)$ under basal conditions and during isoproterenol infusion.

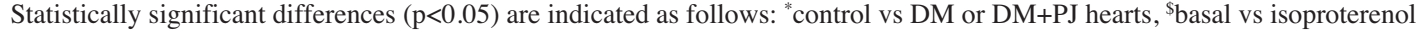

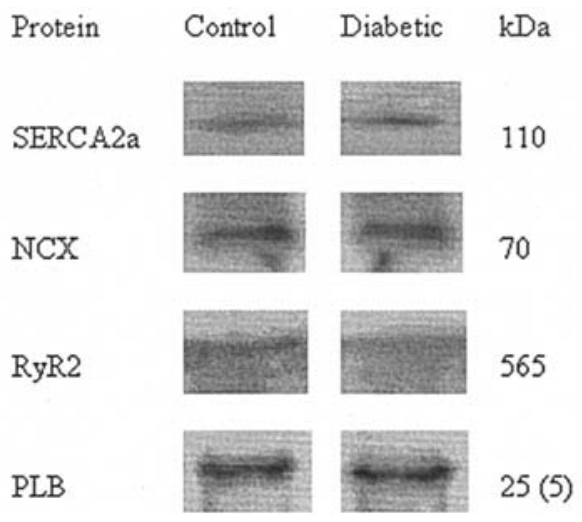

Figure 6. Representative Western blots of SERCA2a, NCX, RyR2 and PLB gained from control and diabetic hearts.

significantly different between control and 6-week diabetic hearts, except for RyR2, which displayed a small but statistically borderline significant decline in the diabetic heart $(p=0.05)$. Because of the lack of appreciable changes in the expression levels of these proteins, no protein determinations were performed in the $\mathrm{DM}+\mathrm{PJ}$ group.

\section{Discussion}

Based on the hemodynamic parameters studied, we conclude that 6 weeks of diabetes in the rat provides a suitable model to investigate alterations in myocardial calcium handling during the transitional state between the apparently normal functioning of the heart and the manifestation of cardiomyopathy. The main findings of this study include an increased end-diastolic $\mathrm{Ca}^{2+}{ }_{\mathrm{i}}$ level, reduced capacity of SERCA2a to sequester calcium
Table III. Expression levels of calcium handling proteins in control $(\mathrm{C}, \mathrm{n}=8)$ and diabetic hearts (6-week diabetic, $\mathrm{n}=7$ ).

\begin{tabular}{llc}
\hline & & Relative intensity \% \\
\hline SERCA2a & C & $95 \pm 3$ \\
& 6-week diabetic & $106 \pm 6$ \\
NCX & C & $101 \pm 2$ \\
& 6-week diabetic & $115 \pm 6$ \\
RyR2 & C & $107 \pm 6$ \\
& 6-week diabetic & $93 \pm 3^{\mathrm{a}}$ \\
Phospholamban & C & $100 \pm 3$ \\
& 6-week diabetic & $110 \pm 10$ \\
\hline
\end{tabular}

Statistically significant differences $(\mathrm{p} \leq 0.05)$ are indicated as follows: ${ }^{\mathrm{a}}$ control vs 6-week diabetic hearts.

and a decline in calcium conductance of RyR2. These changes were not accompanied by major alterations in the tissue content of SERCA2a, RyR2, PLB and NCX.

Diabetic cardiomyopathy. Previous studies have shown that diabetes mellitus caused by destruction of pancreatic $\beta$ cells eventually results in overt decline in cardiac hemodynamic function. The manifestation of diabetic cardiomyopathy is characterized by depressed enzyme activity of myosin because a transition in myosin enzyme composition occurs from $\mathrm{V}_{1}$ to $\mathrm{V}_{3}$ (23). This change in myosin ATPase activity, concurrent with alterations in the function of the regulatory complex of 
troponin and tropomyosin, results in depressed contractile function. Overall, it is well documented that cellular and subcellular remodeling of the diseased heart contributes to the observed contractile dysfunction $(24,25)$. Several lines of evidence indicate that severe alterations in the contractile machinery become manifest 8-12 weeks (4) after the onset of the disease.

We and others have found that, in the basal state, changes in the hemodynamic function of the diabetic heart are absent or very mild during the first $4-5$ weeks of diabetes $(9,10,15,26)$. The collective findings point to a transition state between 4 and 8 weeks in which alterations in contractile performance become manifest. To appreciate the mechanisms underlying the decline in hemodynamic function, research should focus on the changes occurring in the transition phase.

The present study shows early signs of impaired cardiac contractile behavior in the basal state 6 weeks after the onset of the disease. Although the developed pressure did not change, deterioration of both inotropy and lusitropy were already evident under basal conditions in the 6-week diabetic heart. Since intracellular calcium handling plays a pivotal role in cardiac function $(20,27)$, we explored whether primary alterations in the function of calcium channels and transporters underlie the deterioration of hemodynamic performance during this transitional phase.

$\mathrm{Ca}^{2+}{ }_{i}$ handling. One of the major findings of the current study is that end-diastolic $\mathrm{Ca}^{2+}{ }_{\mathrm{i}}$ levels double by the 6th week of diabetes. Moreover, the systolic $\mathrm{Ca}^{2+}{ }_{\mathrm{i}}$ levels also significantly increased in diabetic hearts. Previously, we have shown that 4 weeks of diabetes did not result in significant alterations of intracellular $\mathrm{Ca}^{2+}{ }_{\mathrm{i}}$ levels (15). These observations clearly indicate that, in the transitional phase of the disease, $\mathrm{Ca}^{2+}{ }_{\mathrm{i}}$ overload in the intact diabetic heart develops. In previous studies performed on cardiomyocytes isolated from rodent diabetic hearts, the resting $\mathrm{Ca}^{2+}{ }_{\mathrm{i}}$ levels were found either unchanged or increased $(11,28)$. This apparent lack of consensus may stem from the type of diabetes studied and or the methodology used, i.e. differences in incubation media, stimulus frequency applied, etc. Since, in the present study, $\mathrm{Ca}^{2+}{ }_{\mathrm{i}}$ levels were measured in the intact beating heart, we believe that this study provides direct and relevant information as the cardiomyocytes are functioning within their natural environment. The observed increase in end-diastolic $\mathrm{Ca}^{2+}{ }_{\mathrm{i}}$ levels most likely indicates a diminished SERCA2a function as indicated by the reduction of $\mathrm{V}_{\max }$ of the transporter in the transitional phase of the disease. A negative role for NCX in removing $\mathrm{Ca}^{2+}{ }_{i}$ from the cytoplasm during diastole cannot be excluded since it has been shown that the activity of this protein is decreased in the diabetic heart (13).

Model analysis of $\mathrm{Ca}^{2+}{ }_{i}$ transient. To further delineate the function of SERCA2a and RyR2, we estimated the kinetic parameters of these proteins using a newly developed mathematical approach (15). Considering the model assumptions that NCX does not support a significant calcium flux in the rat heart, this approach proved to be a powerful tool to analyze the characteristics of SERCA2a and RyR2. This model analysis revealed that both maximal rate of calcium influx through
RyR2 $\left(\mathrm{k}_{\mathrm{ch}}\right)$ and maximal transport rate of SERCA2a $\left(\mathrm{V}_{\max }\right)$ were significantly depressed in the diabetic heart under basal conditions. This observation shows malfunction of cardiac calcium handling proteins during the transitional phase. Furthermore, the calculated affinity of SERCA2a to $\mathrm{Ca}^{2+}$ $\left(\mathrm{K}_{\mathrm{m}}\right)$ was not different in the control and diabetic hearts. These findings clearly indicate that the pumping capacity of this transporter is impaired by the disease without a change in the affinity. The calculated decline in capacity to remove $\mathrm{Ca}^{2+}{ }_{\mathrm{i}}$ from the sarcoplasm by SERCA2a to SR is in line with the contention that the observed increased end-diastolic $\mathrm{Ca}^{2+}{ }_{i}$ is caused by alterations in the $\mathrm{Ca}^{2+}$ handling machinery. Furthermore, isoproterenol failed to increase RyR2 conductance significantly in the DM hearts compared to controls indicating a reduced responsiveness of this channel to $\beta$-adrenergic activation. The observed overall effect of $\beta$-adrenergic activation on SERCA2a function in this perfused heart preparation is the expected acceleration of calcium transport. Surprisingly, model calculations revealed increased $\mathrm{V}_{\max }$ and $\mathrm{K}_{\mathrm{m}}$ under these circumstances. Several lines of evidence indicate high rates of reactive oxygen species (ROS) formation in the heart upon acute isoproterenol infusion $(29,30)$. The unexpected reduction in SERCA2a affinity to $\mathrm{Ca}^{2+}$ may well be explained by the ROS induced helix destabilization of phospholamban resulting in a stabile, inhibited state of this $\mathrm{Ca}^{2+}$-ATPase (for review see ref. 31).

An obvious explanation for the alteration of SERCA2a and RyR2 function during the transitional state may stem from the reduced levels of these $\mathrm{Ca}^{2+}$ handling proteins since literature data revealed a decline in the expression level of the major $\mathrm{Ca}^{2+}$ handling proteins during the manifestation of diabetic cardiomyopathy $(4,14,26,32,33)$.

Tissue content of SERCA2a, RyR2, PLB and NCX. In this study, we were unable to show any major reduction in the myocardial tissue content of any of the major $\mathrm{Ca}^{2+}{ }_{\mathrm{i}}$ handling proteins 6 weeks after the onset of STZ-induced diabetes (Table III). Although, numerous studies have provided evidence about changes in the expression levels of the main $\mathrm{Ca}^{2+}{ }_{i}$ handling proteins of the heart in late stages of diabetes (8-12 weeks), in which manifest cardiac failure is already present $(4,14,26,32,33)$, similar data showing signs of derangement of intracellular $\mathrm{Ca}^{2+}{ }_{\mathrm{i}}$ homeostasis during the early stage of diabetes are scarce. Six weeks of diabetes seems to be a transitional period in this respect also since, during this period, some studies showed reduced while others showed increased expression levels of these proteins. For example, Bidasee et al have shown that the expression level of RyR2 was unchanged at 6 weeks of diabetes (14). Furthermore, Zarain-Herzberg et al found no reduction in either SERCA2a mRNA or SERCA2a protein expression at 3-5 weeks of STZinduced diabetes (34). Also, Golfman et al found that gene expression of NCX increased after 3 weeks of induction of diabetes returning to control levels by 5 weeks (35). On the other hand, Hattori et al observed a reduced expression level of cardiac NCX after 4-6 weeks of diabetes (36).

However, it should be emphasized that post-translational changes of these proteins in diabetes may also occur, i.e. glycolisation of various amino acid residues, resulting in 
altered functional properties. These include reduced activity of NCX (13,36), RyR2 (12) and SERCA2a (14). Although we found no major changes in the tissue content of SERCA2a in the present study, we showed that $\mathrm{V}_{\max }$ of SERCA2a in diabetic hearts was reduced to $>50 \%$ of the control hearts, which tended to be a larger difference during $B$-adrenergic activation, i.e. $V_{\max }$ of SERCA2a increased $129 \%$ in DM hearts as compared to the $217 \%$ increase in control hearts $(p=0.07)$. This may be in line with those observations indicating posttranslational changes of this protein resulting in functional impairment of calcium removal from the cytoplasm (14). This notion is also supported by the lack of change in the tissue content of PLB.

According to our results, myocardial RyR 2 content showed a minor albeit significant reduction in diabetic hearts. However, it is unlikely that this reduction in itself accounts for the major decrease in RyR2 conductance, which again was further aggravated by $B$-adrenergic activation. This finding is in accordance with those of Bidasee et al showing that the functional integrity of RyR2 was compromised without any change in its expression level (12). Interestingly enough, $\mathrm{t}_{0.5}$ (the parameter for RyR2 gating) remained unchanged in the diabetic hearts, indicating that the apparent affinity of this channel for calcium did not change at the transitional phase of the disease (12).

Implications of $\mathrm{Ca}^{2+}{ }_{i}$ handling on hemodynamics. In this study, release and removal of $\mathrm{Ca}^{2+}$ were analyzed by two approaches. The crude approaches, $+/-\mathrm{dCa}^{2+}{ }_{\mathrm{i}} / \mathrm{dt}_{\max }$, failed to reveal differences in these processes under basal conditions and, hence, were unable to explain the observed depression in $+/-d P / d_{\max }$. In contrast, model calculations to estimate the kinetic parameters of RyR2 and SERCA2a revealed that $\mathrm{Ca}^{2+}$ influx through the ryanodine channel and removal of calcium by SERCA2a were depressed under basal conditions and in response to $B$-adrenergic activation in diabetic hearts compared to controls. The malfunction of these calcium handling proteins is consistent with the observed reduction in inotropy and lusitropy, $+/-\mathrm{dP} / \mathrm{dt}_{\max }$, in diabetic cardiomyopathy. In summary, clarification of the underlying mechanisms responsible for the contractile dysfunction of the intact diabetic heart during the transitional phase requires a detailed analysis of the $\mathrm{Ca}^{2+}{ }_{\mathrm{i}}$ transient to reveal changes in $\mathrm{Ca}^{2+}{ }_{\mathrm{i}}$ handling in conjunction with impaired hemodynamic performance.

Role of PARP in the function of the diabetic heart and effects on $\mathrm{Ca}^{2+}{ }_{i}$ handling. Previous in vivo studies demonstrated that diabetes mellitus in rats and mice can lead to suppressed cardiac contractility in vivo, which can be improved by PARP inhibition (including the currently used PARP inhibitor, PJ34) (5). In contrast, in the current study, we have only observed relatively minor changes in the hearts of PARP inhibitor-treated animals. As the current model represents a transitional stage between healthy and diseased mycardium, it is possible that, at this stage of the disease, PARP-dependent alterations are not yet manifest. PARP-dependent alterations, in general, occur in response to severe oxidative or nitrosative stress (8), and this may not yet be significant in the currently studied stage of diabetes. Nevertheless, we have noted some interesting trends in response to PJ34 treatment, such as reduced weight loss despite the identical degree of hyperglycemia (which may be consistent with a general improvement of the health of the animals), as well as some trends for improved myocardial calcium handling in some calculated parameters (Fig. 5, $\mathrm{V}_{\max }$ and $\mathrm{k}_{\mathrm{ch}}$ ). In a recent study, we noted that PARP inhibition significantly improves myocardial contractility and calcium handling in a severe model of myocardial dysfunction elicited by the cardiotoxic drug, doxorubicin (16). Since both doxorubicin cardiomyopathy and severe diabetic cardiomyopathy, which may not be applicable to the current model but may develop in later stages of the disease, have a significant oxidant and free radical mediated component, it will be interesting to study whether PARP plays a role in the pathogenesis of diabetic cardiomyopathy and disturbed calcium handling in later stages of the disease.

In the present study, we have shown that, in the transitional state of diabetes from apparently normal to overt cardiac malfunctioning, the end-diastolic $\mathrm{Ca}^{2+}{ }_{\mathrm{i}}$ levels are increased. We have also shown that, for the impairment of the inotropic and lusitropic state of the heart, functional changes of the $\mathrm{Ca}^{2+}{ }_{i}$ handling proteins are responsible rather than the expression levels of these proteins. Overall, in this transitional phase of diabetes, there are clear signs of disturbances in $\mathrm{Ca}^{2+}{ }_{\mathrm{i}}$ handling which are most likely to be attributable to functional disturbances of SERCA2a and RyR2. The results also show that, at the current stage of diabetes, the nuclear enzyme, PARP, does not appear to play a significant pathogenetic role in the alterations in contractile function and calcium handling.

\section{Acknowledgements}

This work was supported by grants from OTKA (Hungarian Research Fund, T038121, T047095, T042969 and K61694), by a grant from the European Foundation for the Study of Diabetes, and by the Socrates program of the European Community and the Department of Biomedical Engineering, Eindhoven University of Technology, Eindhoven, The Netherlands.

\section{References}

1. Fein FS, Kornstein LB, Strobeck JE, Capasso JM and Sonnenblick EH: Altered myocardial mechanics in diabetic rats. Circ Res 47: 922-933, 1980.

2. Galderisi M, Anderson KM, Wilson PW and Levy D: Echocardiographic evidence for the existence of a distinct diabetic cardiomyopathy (the Framingham Heart Study). Am J Cardiol 68: 85-89, 1991 .

3. Pierce GN and Russell JC: Regulation of intracellular $\mathrm{Ca}^{2+}$ in the heart during diabetes. Cardiovasc Res 34: 41-47, 1997.

4. Choi KM, Zhong Y, Hoit BD, et al: Defective intracellular $\mathrm{Ca}^{2+}$ signaling contributes to cardiomyopathy in type 1 diabetic rats. Am J Physiol 283: H1398-H1408, 2002.

5. Pacher P, Liaudet L, Soriano FG, Mabley JG, Szabo E and Szabo C: The role of poly(ADP-ribose) polymerase activation in the development of myocardial and endothelial dysfunction in diabetes. Diabetes 51: 514-521, 2002.

6. Szabo C, Mabley JG, Moeller SM, et al: Part I: pathogenetic role of peroxynitrite in the development of diabetes and diabetic vascular complications: studies with FP15, a novel potent peroxynitrite decomposition catalyst. Mol Med 8: 571-580, 2002.

7. Jagtap P and Szabo C: Poly(ADP-ribose) polymerase and the therapeutic effects of its inhibitors. Nat Rev Drug Discov 4: 421-440, 2005. 
8. Pacher P, Schulz R, Liaudet L and Szabo C: Nitrosative stress and pharmacological modulation of heart failure. Trends Pharmacol Sci 26: 302-310, 2005.

9. Depre C, Young ME, Ying J, et al: Streptozotocin-induced changes in cardiac gene expression in the absence of severe contractile dysfunction. J Mol Cell Cardiol 32: 985-996, 2000.

10. Mihm MJ, Seifert JL, Coyle CM and Bauer JA: Diabetes related cardiomyopathy time-dependent echocardiographic evaluation in an experimental rat model. Life Sci 69: 527-542, 2001.

11. Yu JZ, Rodrigues B and McNeill JH: Intracellular calcium levels are unchanged in the diabetic heart. Cardiovasc Res 34: 91-98, 1997.

12. Bidasee KR, Dincer UD and Besch HR Jr: Ryanodine receptor dysfunction in hearts of streptozotocin-induced diabetic rats. Mol Pharmacol 60: 1356-1364, 2001

13. Schaffer SW, Ballard-Croft C, Boerth S and Allo SN: Mechanisms underlying depressed $\mathrm{Na}^{+} / \mathrm{Ca}^{2+}$ exchanger activity in the diabetic heart. Cardiovasc Res 34: 129-136, 1997.

14. Bidasee KR, Zhang Y, Shao CH, et al: Diabetes increases formation of advanced glycation end products on Sarco(endo)plasmic reticulum $\mathrm{Ca}^{2+}$-ATPase. Diabetes 53: 463-473, 2004.

15. Op den Buijs J, Miklos Z, van Riel NA, et al: Beta-adrenergic activation reveals impaired cardiac calcium handling at early stage of diabetes. Life Sci 76: 1083-1098, 2005.

16. Szenczi O, Kemecsei P, Holthuijsen MFJ, et al: Poly(ADPribose) polymerase regulates myocardial calcium handling in doxorubicin-induced heart failure. Biochem Pharmacol 69 : 725-732, 2005

17. Pacher P, Liaudet L, Mabley J, Komjati K and Szabo C: Pharmacologic inhibition of poly(adenosine diphosphate-ribose) polymerase may represent a novel therapeutic approach in chronic heart failure. J Am Coll Cardiol 40: 1006-1016, 2002.

18. Grynkiewicz G, Poenie M and Tsien RY: A new generation of $\mathrm{Ca}^{2+}$ indicators with greatly improved fluorescence properties. J Biol Chem 260: 3440-3450, 1985 .

19. Bassani JW, Bassani RA and Bers DM: Calibration of indo-1 and resting intracellular $\left[\mathrm{Ca}^{2+}\right] \mathrm{i}$ in intact rabbit cardiac myocytes. Biophys J 68: 1453-1460, 1995.

20. Bers DM: Calcium fluxes involved in control of cardiac myocyte contraction. Circ Res 87: 275-281, 2000.

21. Wagner J and Keizer J: Effects of rapid buffers on $\mathrm{Ca}^{2+}$ diffusion and $\mathrm{Ca}^{2+}$ oscillations. Biophys J 67: 447-456, 1994.

22. Bradford MM: A rapid and sensitive method for the quantitation of microgram quantities of protein utilizing the principle of protein-dye binding. Anal Biochem 72: 248-254, 1976.

23. Malhotra A, Reich D, Reich D, et al: Experimental diabetes is associated with functional activation of protein kinase $\mathrm{C}$ epsilon and phosphorylation of troponin I in the heart, which are prevented by angiotensin II receptor blockade. Circ Res 81: 1027-1033, 1997.
24. Ozdemir S, Ungur M, Gurdal H and Turan B: Treatment with AT(1) receptor blocker restores diabetes-induced alterations in intracellular $\mathrm{Ca}(2+)$ transients and contractile function of rat myocardium. Arch Biochem Biophys 435: 166-174, 2005.

25. Mozaffari MS, Wilson GL and Schaffer SW: Effect of chronic sulfonylurea treatment on the myocardium of insulin-dependent diabetic rats. Can J Physiol Pharmacol 66: 1481-1486, 1988

26. Zhong Y, Ahmed S, Grupp IL and Matlib MA: Altered SR protein expression associated with contractile dysfunction in diabetic rat hearts. Am J Physiol 281: H1137-H1147, 2001.

27. Balke CW, Egan TM and Wier WG: Processes that remove calcium from the cytoplasm during excitation-contraction coupling in intact rat heart cells. J Physiol 474: 447-462, 1994.

28. Allo SN, Lincoln TM, Wilson GL, Green FJ, Watanabe AM and Schaffer SW: Non-insulin-dependent diabetes-induced defects in cardiac cellular calcium regulation. Am J Physiol 260: C1165-C1171, 1991

29. Tappia PS, Hata T, Hozaima L, Sandhu MS, Panagia V and Dhalla NS: Role of oxidative stress in catecolamine-induced changes in cardiac sarcolemmel $\mathrm{Ca}^{2+}$ transport. Arch Biochem Biophys 387: 85-92, 2001.

30. Zhang GX, Kimura S, Nishiyama A, et al: Cardiac oxidative stress in acute and chronic isoproterenol-infused rats. Cardiovasc Res 65: 230-238, 2005.

31. Bigelow DJ and Squier TC: Redox modulation of cellular signaling and metabolism through reversible oxidation of methionine sensors in calcium regulatory proteins. Biochim Biophys Acta 1703: 121-134, 2005.

32. Trost SU, Belke DD, Bluhm WF, Meyer M, Swanson E and Dillmann WH: Overexpression of the sarcoplasmic reticulum $\mathrm{Ca}(2+)$-ATPase improves myocardial contractility in diabetic cardiomyopathy. Diabetes 51: 1166-1171, 2002.

33. Vetter R, Rehfeld U, Reissfelder C, et al: Transgenic overexpression of the sarcoplasmic reticulum $\mathrm{Ca}^{2+}$ ATPase improves reticular $\mathrm{Ca}^{2+}$ handling in normal and diabetic rat hearts. FASEB J 16: 1657-1659, 2002 .

34. Zarain-Herzberg A, Yano K, Elimban V and Dhalla NS: Cardiac sarcoplasmic reticulum $\mathrm{Ca}(2+)$-ATPase expression in streptozotocin-induced diabetic rat heart. Biochem Biophys Res Commun 203: 113-120, 1994.

35. Golfman L, Dixon IM, Takeda N, Lukas A, Dakshinamurti K and Dhalla NS: Cardiac sarcolemmal $\mathrm{Na}(+)-\mathrm{Ca}^{2+}$ exchange and $\mathrm{Na}(+)-\mathrm{K}^{+}$ATPase activities and gene expression in alloxaninduced diabetes in rats. Mol Cell Biochem 188: 91-101, 1998.

36. Hattori Y, Matsuda N, Kimura J, et al: Diminished function and expression of the cardiac $\mathrm{Na}^{+}-\mathrm{Ca}^{2+}$ exchanger in diabetic rats: implication in $\mathrm{Ca}^{2+}$ overload. J Physiol 527: 85-94, 2000. 